\title{
Flow Structure Around Marginal Bank with Different Slopes Under the Action of Unsteady Flow
}

\author{
Pingyi Wang ${ }^{1}$,Ye Tian ${ }^{2}$, Genting Guo ${ }^{3}$, Meili Wang ${ }^{4}$ \\ 1 National Inland Waterway Regulation Engineering Technology Research Center, Chongqing Jiaotong University, \\ Chongqing 400074,China;Email: py-wang@163.com \\ 2 National Inland Waterway Regulation Engineering Technology Research Center, Chongqing Jiaotong University, \\ Chongqing 400074,China;Email: 1411162874@qq.com. \\ 3 National Inland Waterway Regulation Engineering Technology Research Center, Chongqing Jiaotong University, \\ Chongqing 400074,China;Email: hermesguo@163.com. \\ ${ }^{4}$ School of Architecture and Urban Planning, Chongqing Jiaotong University, Chongqing 400074 ,China; \\ Email:wm19106@163.com.
}

Correspondence Email: 1411162874@qq.com.

\begin{abstract}
Unsteady flow is the most common and complicated form of fluid motion in nature. This paper takes the beaches of key waterways in the middle and lower reaches of the Yangtze River as the research object, analyzes the water surface distribution and average flow velocity distribution near the beach, and analyzes the differences. The relationship between the flow pattern of the steep slope and the water flow pattern of the entire survey area and the steep slope of the beach and its nearby water flow structure. The water flow near the beach is divided into four major blocks: the swelling water area, the falling water area, the backwater area and the maximum flow rate area. The water flow structure characteristics and the cause of each block are analyzed.
\end{abstract}

Key words: marginal bank; unsteady flow; different slopes; water flow structure; experimentation; Yangtze River

\section{Introduction}

The beach usually refers to a large-scale, morphologically shaped silt distributed in an alluvial river channel with a certain scale of silt, which is an important part of the river channelError! Reference source not found..Under the influence of the erosion and sedimentation of natural rivers, most of the beaches without protection and control measures will undergo erosion and siltation changes and even displacement, thus losing their stable river banks and landscaping, maintaining dry water troughs and controlling river channel patterns. Many waterway improvement projects are carried out to protect and control the beach body with the above functions. Studying the water flow structure near the beach is of great significance for understanding the evolution characteristics of the beach and the stability and reinforcement of the project.

At present, there are few studies on the flow structure near the regulation buildings. KabiriError! Reference source not found. studied the flow structure over a wavy bed with vegetation cover. HuaError! Reference source not found. studied flow structure in braided rivers. AyseError! Reference source not found. 
studied the flow structure in a compound open-channel flow.Wang et al.Error! Reference source not found. studied the shape of the main beaches in the middle reaches of the Yangtze River, the structural forms of the beach protection belts, the simulation techniques, protection of the beach belts and beach remediation effect. The local water flow structure near the beach is very complex, exhibiting dramatic three-dimensional turbulence characteristics, and even causing high turbulence intensity and free surface changes and other water flow phenomena. It is a common consensus that the presence of the beaches causes a significant change in the flow of water near the beach. However, the influence of the shape of the beach, especially the slope of the steep slope at the junction of the beachhead and the beach channel, on the water flow near the beach is remains to be discussed. This study explored this problem through water tank experiment. Based on the middle and lower reaches of the Yangtze River, this paper analyzes the different surface shoals (mainly the steep slope) under different unsteady flow processes. The distribution law within the area.

\section{Model test}

\subsection{Model design}

The X-shaped mattress generalized model test was carried out in a rectangular glass tank test system of $L 30 m \times W 2 m \times H 1 m$. The tank test system is located in the waterway remediation test hall of the National Inland Waterway Regulation Engineering Technology Research Center, including the flow control system and the circulating water system. This study does not simulate a specific project or river section, but generalizes the prototype data, simulates part of the project length, and makes the tank test flow process have some similar scale relationship with the natural river. The characteristics of the prototype shoal in the middle and lower reaches of the Yangtze River are analyzed. The basic characteristics of the important channel shoal (beach) in the middle and lower reaches of the Yangtze River are as shown in Table 1. The model beach is generalized, and the shrinkage ratio and aspect ratio of the test shoal are determined by the geometric characteristics of the original beach body in the range of mean \pm standard deviation (0.28 0.52) and (4 8.8). The average slope of the longitudinal (water flow direction) of the beach is $3.8 \%$, and the lateral slope is divided into two sections: gentle slope and steep slope. The gentle slope is $1.5 \%$ and the steep slope is $8 \%$.

Table 1 Basic characteristic parameters of the main channel of the Yangtze River

\begin{tabular}{|c|c|c|c|c|c|c|c|c|}
\hline Case & Waterway & $\begin{array}{l}\text { Channel } \\
\text { width } \\
(\mathrm{km})\end{array}$ & $\begin{array}{l}\text { Beach } \\
\text { body }\end{array}$ & Shape & $\begin{array}{l}\text { Beach } \\
\text { length } \\
(\mathrm{km})\end{array}$ & $\begin{array}{l}\text { Beach } \\
\text { width } \\
(\mathrm{km})\end{array}$ & $\begin{array}{l}\text { Beach } \\
\text { height } \\
(\mathrm{m})\end{array}$ & Width ratio \\
\hline 1 & $\begin{array}{l}\text { Yidu } \\
\text { Waterway }\end{array}$ & 1. $1 \sim 1.8$ & $\begin{array}{l}\text { Shakan } \\
\text { wan } \\
\text { Beach }\end{array}$ & $\begin{array}{l}\text { Straight } \\
\text { beach }\end{array}$ & $2.1 \sim 3.0$ & $0.20 \sim 0.50$ & $0 \sim 6.0$ & $0.11 \sim 0.45$ \\
\hline 2 & $\begin{array}{l}\text { Lujiahe } \\
\text { Waterway }\end{array}$ & $1.0 \sim 2.2$ & $\begin{array}{l}\text { Yangjia } \\
\text { lao } \\
\text { beach }\end{array}$ & $\begin{array}{l}\text { Micro-ben } \\
\text { d convex }\end{array}$ & $0.6 \sim 0.8$ & $0.27 \sim 0.66$ & $0 \sim 5.9$ & $0.12 \sim 0.66$ \\
\hline
\end{tabular}


beach

\begin{tabular}{|c|c|c|c|c|c|c|c|c|}
\hline 3 & $\begin{array}{l}\text { Majiaju } \\
\text { Waterway }\end{array}$ & $1.0 \sim 4.0$ & $\begin{array}{l}\text { Baiweiz } \\
\text { hou } \\
\text { Beach }\end{array}$ & $\begin{array}{l}\text { Straight } \\
\text { beach }\end{array}$ & $2.1 \sim 3.0$ & $0.20 \sim 0.40$ & $0 \sim 6.0$ & $0.05^{\sim} 0.40$ \\
\hline 4 & $\begin{array}{l}\text { Zhougong } \\
\text { Waterway }\end{array}$ & $0.8 \sim 1.8$ & $\begin{array}{l}\text { Jiaoziyu } \\
\text { an } \\
\text { Beach }\end{array}$ & $\begin{array}{l}\text { Micro-ben } \\
\text { d concave } \\
\text { bank }\end{array}$ & $4.0 \sim 6.2$ & $0.30 \sim 0.50$ & $0 \sim 6.0$ & $0.17 \sim 0.63$ \\
\hline 5 & $\begin{array}{l}\text { Jieshui } \\
\text { Waterway }\end{array}$ & $1.6 \sim 1.8$ & $\begin{array}{l}\text { Luosha } \\
\text { n Beach }\end{array}$ & $\begin{array}{l}\text { Straight } \\
\text { beach }\end{array}$ & $3.6 \sim 4.5$ & $0.40 \sim 1.12$ & $0 \sim 3.1$ & $0.22 \sim 0.68$ \\
\hline 6 & $\begin{array}{l}\text { Jiayu } \\
\text { Waterway }\end{array}$ & $1.3 \sim 4.2$ & $\begin{array}{l}\text { Wangji } \\
\text { azhou } \\
\text { Beach }\end{array}$ & $\begin{array}{l}\text { Straight } \\
\text { beach }\end{array}$ & $3.1 \sim 4.5$ & $0.15^{\sim} 0.70$ & $0 \sim 5.2$ & $0.04 \sim 0.54$ \\
\hline 7 & $\begin{array}{l}\text { Wuqiao } \\
\text { Waterway }\end{array}$ & $1.1 \sim 2.0$ & $\begin{array}{l}\text { Hanyan } \\
\text { g Beach }\end{array}$ & $\begin{array}{l}\text { Straight } \\
\text { beach }\end{array}$ & $1.6 \sim 3.5$ & $0.36 \sim 0.82$ & $0 \sim 5.0$ & $0.18 \sim 0.75$ \\
\hline 8 & $\begin{array}{l}\text { Huguang } \\
\text { Waterway }\end{array}$ & $0.9 \sim 1.4$ & $\begin{array}{l}\text { Weijiat } \\
\text { an } \\
\text { Beach }\end{array}$ & $\begin{array}{l}\text { Straight } \\
\text { beach }\end{array}$ & $1.5^{\sim} 2.6$ & $0.51 \sim 0.67$ & $0 \sim 4.0$ & $0.36 \sim 0.74$ \\
\hline 9 & $\begin{array}{l}\text { Guniusha } \\
\text { Waterway }\end{array}$ & $1.1 \sim 1.4$ & $\begin{array}{l}\text { Yak } \\
\text { Guniuz } \\
\text { hou } \\
\text { Beach }\end{array}$ & $\begin{array}{l}\text { Straight } \\
\text { beach }\end{array}$ & $2.1 \sim 2.3$ & $0.58 \sim 0.64$ & $0 \sim 13.6$ & $0.41 \sim 0.58$ \\
\hline 10 & $\begin{array}{l}\text { Yaojinao } \\
\text { waterway }\end{array}$ & $1.0 \sim 1.3$ & $\begin{array}{l}\text { Yanggo } \\
\text { uzi } \\
\text { Beach }\end{array}$ & $\begin{array}{l}\text { Straight } \\
\text { beach }\end{array}$ & $3.0 \sim 6.0$ & $0.30 \sim 0.60$ & $0 \sim 5.9$ & $0.23 \sim 0.60$ \\
\hline
\end{tabular}

Select the X-shaped mattress as the protection of the beach structure in this study, according to the resource of Wang et al.Error! Reference source not found.. According to the research results, the model scale is initially determined to be 1:10. According to the geometric characteristics of the prototype X-shaped mattress, the geometrical dimensions of the model pressure carrier can be obtained: $4.5 \mathrm{~cm} \times 4.0 \mathrm{~cm} \times 1.0 \mathrm{~cm}$ (length $\times$ width $\times$ thickness), and the mass is $43.20 \mathrm{~g}$. The density is $2400 \mathrm{~kg} / \mathrm{m} 3$. The geometric characteristics of the test shoal are shown in Table 2. 
Table 2 Geometric characteristics of test beach body

\begin{tabular}{lllllllll}
\hline & & Body & $\begin{array}{l}\text { Tail } \\
\text { length }\end{array}$ & $\begin{array}{l}\text { Beachhead } \\
\text { Length }\end{array}$ & $\begin{array}{l}\text { Straight } \\
\text { length }\end{array}$ & $\begin{array}{l}\text { Body } \\
\text { Width }\end{array}$ & $\begin{array}{l}\text { Steep } \\
\text { slope }\end{array}$ & Gentle \\
& Height & length & Slope & gradient \\
\hline I & & 590 & 310 & 200 & 80 & 120 & 0.12 & 0.015 \\
II & 12 & 590 & 310 & 200 & 80 & 120 & 0.16 & 0.015 \\
III & 590 & 310 & 200 & 80 & 120 & 0.20 & 0.015 \\
\hline
\end{tabular}

\subsection{Test schemes}

This test mainly studies the hydraulic characteristics near the beach, so the clear water bed test is used. Taking into account the water supply capacity of the water supply equipment, the maximum flow rate considering the flow process in the case of three geometric similarities and similar water flow movements is designed in the model as $\mathrm{Q}=93 \mathrm{l}$ /s, 145 1/s, 166 1/s. The test conditions are shown in Table 3 .

Table 3 Test conditions table

\begin{tabular}{llll}
\hline Case & Number & Flow process $(\mathrm{L} / \mathrm{s})$ & Slope \\
\hline M1 & I & 93 & 0.12 \\
M2 & I & 145 & 0.12 \\
M3 & I & 166 & 0.12 \\
M4 & II & 93 & 0.16 \\
M5 & II & 145 & 0.16 \\
M6 & II & 166 & 0.16 \\
M7 & III & 93 & 0.20 \\
M8 & III & 145 & 0.20 \\
M9 & III & 166 & 0.20 \\
\hline
\end{tabular}




\subsection{Arrangement of test points}

\subsubsection{Flow velocity measurement}

$\mathrm{X}$-shaped soft row intention is shown in Figure 1. Flow rate measuring point arrangement is shown in Figure 2. In order to observe the flow velocity distribution near the beach and the surface of the beach under various working conditions, the velocity measuring point section should cover the upstream to the downstream section of the beach, so some additional arrangements are needed. In the test, a total of 12 flow velocity measuring sections were arranged. The flow patterns in the vicinity of the beach tail and the upper and lower shoal bodies were smaller, so the spacing of the measuring points was slightly larger. The flow state of the beachheads was larger, so the spacing of the measuring points was slightly smaller.

The change of flow state on the beach is larger than that of other locations. The distance between the measuring points of each section is $20 \mathrm{~cm}$ on the beach and $25 \mathrm{~cm}$ in the channel. If all the sections are equipped with measuring instruments at the same time, it will have a non-negligible influence on the water flow near the beach. In order to reduce the impact, each water discharging process in the test only selects two sections with far spacing, and the interval between each water discharge test is large in the far two sections, a random flow process was repeated 6 times to complete the flow measurement of 12 sections.

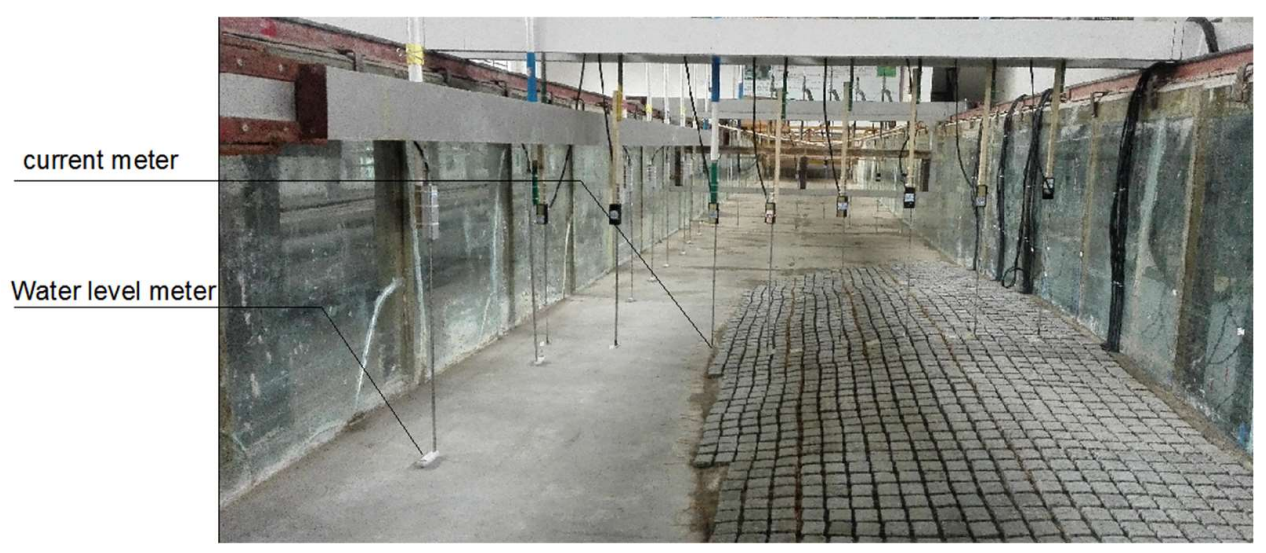

Figure $1 \mathrm{X}$-shaped soft row intention (unit: $\mathrm{cm}$ )

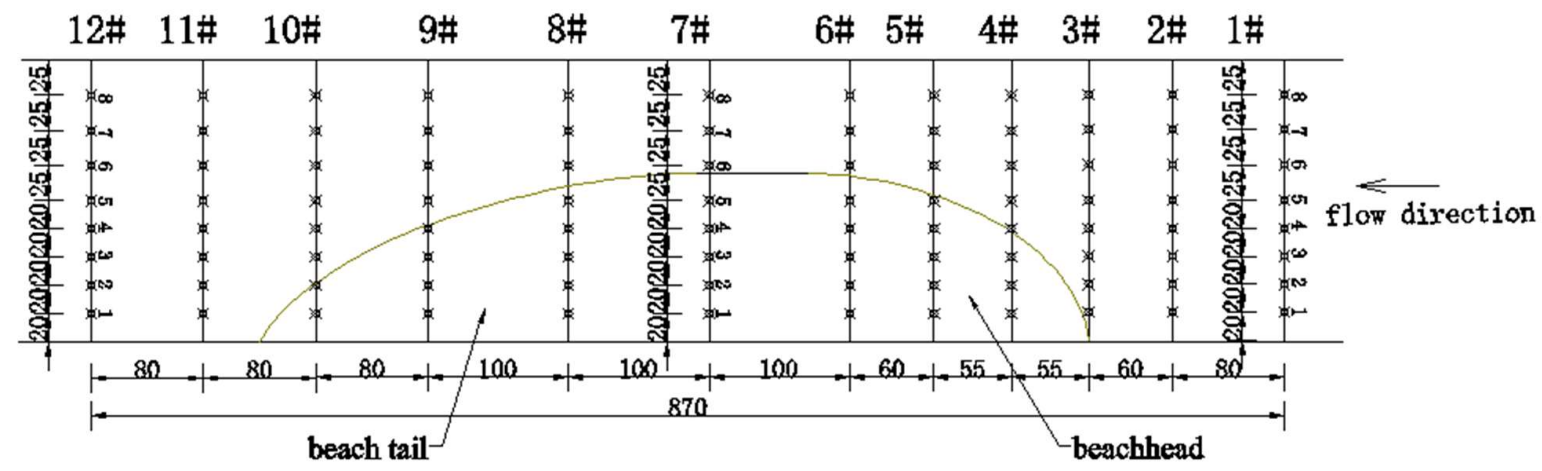

Figure 2 Layout of velocity measurement points (unit: $\mathrm{cm}$ ) 


\subsubsection{Water level measurement}

In order to observe the water surface line under various working conditions, a number of water level test longitudinal sections are arranged, the water level measuring point and the flow rate measuring point are in the same position, and the water level test section numbering sequence is V1\#、V3\#、V4\#、V5\#、V6\#、V8\# from the left bank to the right bank, specific arrangement as Figure 3 shown, unit $\mathrm{cm}$. Water level measurement section and flow rate measurement section combined measurement is adopted in this test.

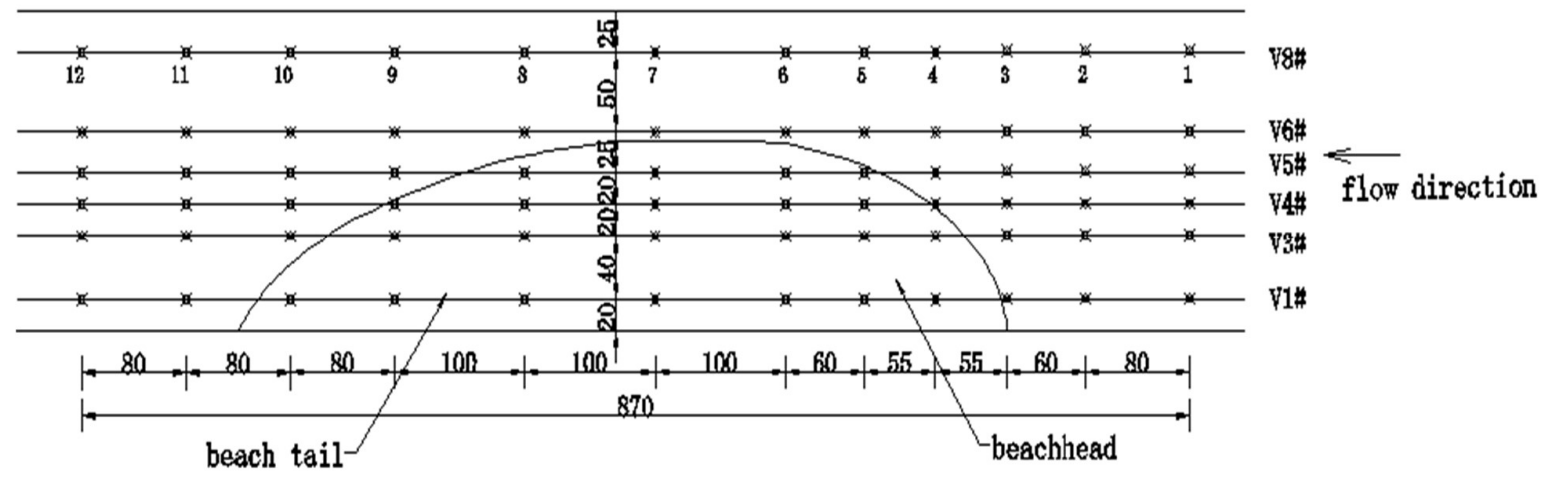

Figure 3 Layout of water level survey points

\subsection{Test measurement system}

\subsubsection{Water level and flow measurement}

The synchronous automatic measuring system used for water level measurement was developed by Southwest China Water Transport Science Research Institute. Ultrasonic water level gauge and automatic tracking system. The system uses the ultrasonic ranging principle, combined with advanced sensing technology and electronic technology, to simultaneously collect and record the water level data of different measuring points. The data can be fed back to the user interface in real time and accurately, so that the observer can grasp the water level change of the measuring point in time. The inlet flow is controlled by the DCMS flow control system.

\subsubsection{Flow rate measurement}

The single-point near-surface velocity measurement is measured by the slurry flow meter developed by Southwest China Water Transport Science Research Institute. The acquisition frequency is $100 \mathrm{~Hz}$. The pulse sampling method is used. The sampling duration of each point is equal to the duration of the non-constant flow process, which is 24940s. The flow rate data acquisition used the long-time tracking acquisition system for the transient flow rate was developed by the Hohai College of Chongqing Jiaotong University, and the sampling frequency was 3000 /s. 


\section{Results and analyses}

\subsection{Water surface line distribution}

In order to facilitate the comparative analysis, the water level of the measuring points on the three longitudinal sections of V1\#, V5\# and V8\# is selected as the characteristic longitudinal section of the analysis of this part. The three sections pass through the top of the beach, the steep slope of the beach, and the longitudinal section of the deep trough. They are well represented in the topographical changes. The V1\# section passes the top of the beach and the terrain is the most undulating; V5\# passes through the steep slope of the beach and changes the terrain is the sharpest; V8\# passes through the deep trough, and the terrain is basically flat.

\subsubsection{Longitudinal water surface distribution}

Due to the presence of the beach, the longitudinal flow line of the incoming flow will undergo significant changes. Due to the narrow water flow in the upper part of the beach, local flooding phenomenon will occur, and the water level will rise. Local water fall will occur near the middle reaches of the beach, and the water level will drop significantly. The water flow in the downstream of the beach will widen and the water level will gradually rise smooth. The water level of each measuring point of the longitudinal section under different flow rates of case M8 is shown in Figure 4.

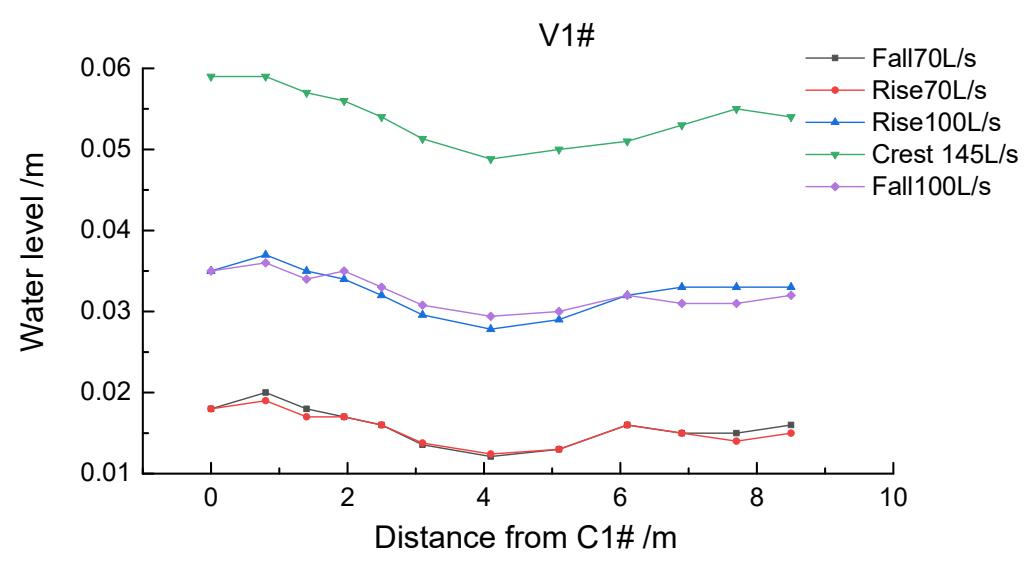



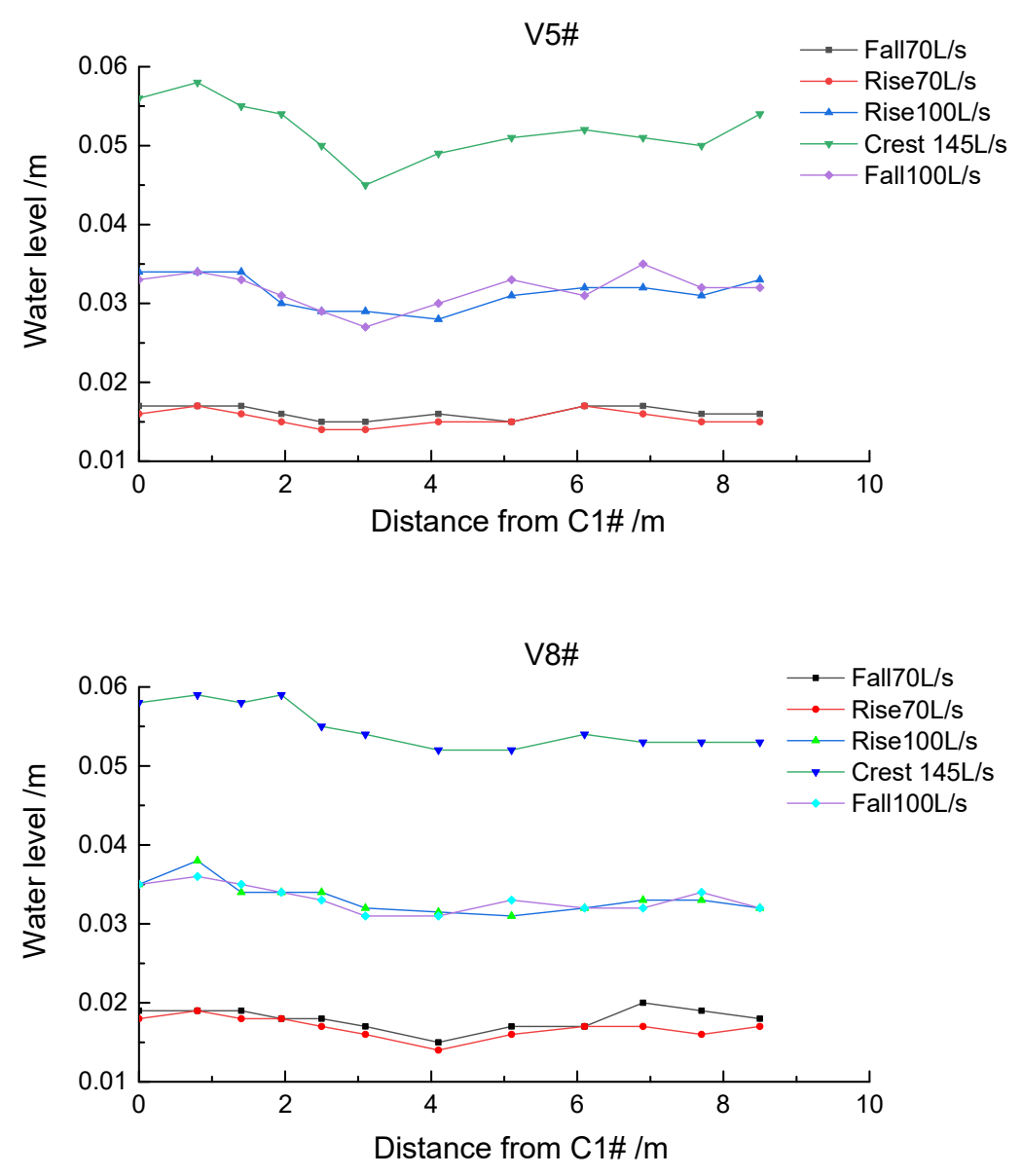

Figure 4 Water level of longitudinal section under different operating conditions at M8

Compared with the water surface line under different flow rates of the same section, it mainly starts from the maximum slope and the changing trend of the water surface line. The maximum slope reflects the rate of change of the water level along the way, while the trend reflects the local variation of the water level. Comparing the three sections of V1\#, V5\# and V8\#, it can be found that the lowest water level of each longitudinal section appears at a position about $4 \mathrm{~m}$ away from the $\mathrm{C} 1$ \# section, that is, near the C7\# section, indicating that the upper part of the beach is drowning. A slight drop in the straight section of the shoal body occurred until C7\# fell to a minimum, then the water level began to rise and reached the downstream tail water level, which showed that the water level above and below the beach was higher than the water level in the middle of the beach. Comparing the water surface line of the rising water 100L/s of each section and the falling water of $100 \mathrm{~L} / \mathrm{s}$, the variation of the water level is basically the same, that is, the maximum slope of the water surface line is basically the same, the overall shape of the water surface line is basically the same, and the water surface line of the water depth of each section the rising water $70 \mathrm{~L} / \mathrm{s}$ and falling water $70 \mathrm{~L} / \mathrm{s}$ also conforms to this rule, indicating that the ups and downs of the flood period have little effect on the water surface line. Comparing the water surface lines at 5 flow rates of each section, the larger the flow rate, the higher the water level at the corresponding position. This rule is the same as the constant flow condition. The change of the water level along the path is more obvious, that is, the larger the maximum slope of the water 
surface line, but the water surface the overall shape of the line is basically the same. Taking the V1\# section as an example, the maximum slopes of the water surface lines of flow rates $145 \mathrm{~L} / \mathrm{s}, 100 \mathrm{~L} / \mathrm{s}$, and $70 \mathrm{~L} / \mathrm{s}$ are $0.24 \%$, $0.17 \%$, and $0.15 \%$, respectively, but the corresponding water line changes. The trend is that the middle part is slightly bent down, and the two ends are gentle, which means that the flow rate has a significant influence on the slope of the water surface line, and the change trend is not obvious. The water level change of the longitudinal water surface line is mainly concentrated in the range of $2 \mathrm{~m}-6 \mathrm{~m}$ from the C1\# section ( C4\# C9\#), which is the main part of the beach body, which fully shows that the impact of the beach body on the longitudinal water surface line is significant.

Compared with the water surface line of each section at the same flow rate, it can be found that the water surface line of the V5\# section changes most sharply under the same flow rate, and V1\# is the second, and V8\# is the most gentle. V5\# has obvious water drop at a position of about $3 \mathrm{~m}$ from the C1\# section. Then the water level rises and the water surface line has a steep rise and fall, while the V1\# and V8\# water surface lines are basically flat and rising. There is a obvious curved section in the middle of the V1\# section of the water surface line, and the V8\# water surface line is relatively straight. This is because the V5\# section passes the steep slope and curved section of the beach, and the narrow water flow phenomenon of the beach is the most at the $3 \mathrm{~m}$ section of the V5\# section. Obviously, the flow state of the water flow is the most severe. The V1\# section passes through the top of the beach,the shape steeply increases first and then decreases. and V8\# terrain is relatively flat. It can be seen from the above analysis that the influence of the topography on the water surface line is more significant, and the position of the water surface line is most obvious when the terrain changes more severely and more complicated.

\subsubsection{Transverse water surface distribution}

Due to the hindrance of the beach body to the water flow, when the water is in the vicinity of the beach body, the flow direction of the left bank water changes, resulting in a corresponding change in the water surface line of a part of the cross section. Analysis of the transverse surface line can help to understand the effect of the beach on the flow in the transverse direction. In order to facilitate analysis and comparison, the measurement points on the cross sections of five representative features of C1\#, C5\#, C7\#, C9\#, and C12\# are selected as the analysis objects of this part. C1\#, C5\#, C7\#, C9\#, and C12\# are located in the upstream of the beach, the curved section of the beachhead, the straight section of the beach, the curved section of the beach tail, and the downstream of the beach. Selecting the representative case M8, the water level of each measuring point on the cross section of the five characteristic positions under five characteristic flows is shown in Figure 5.

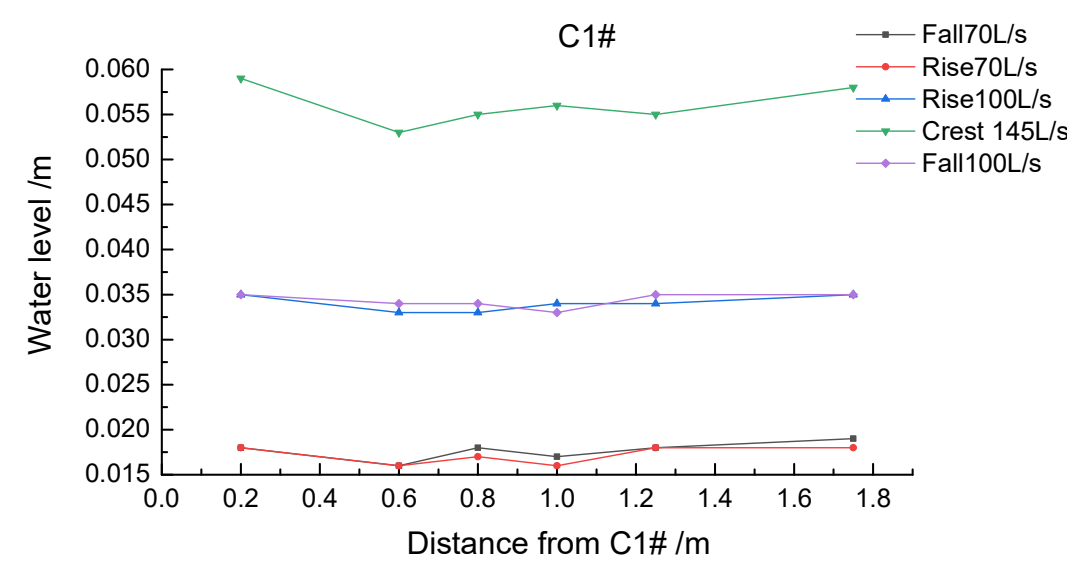



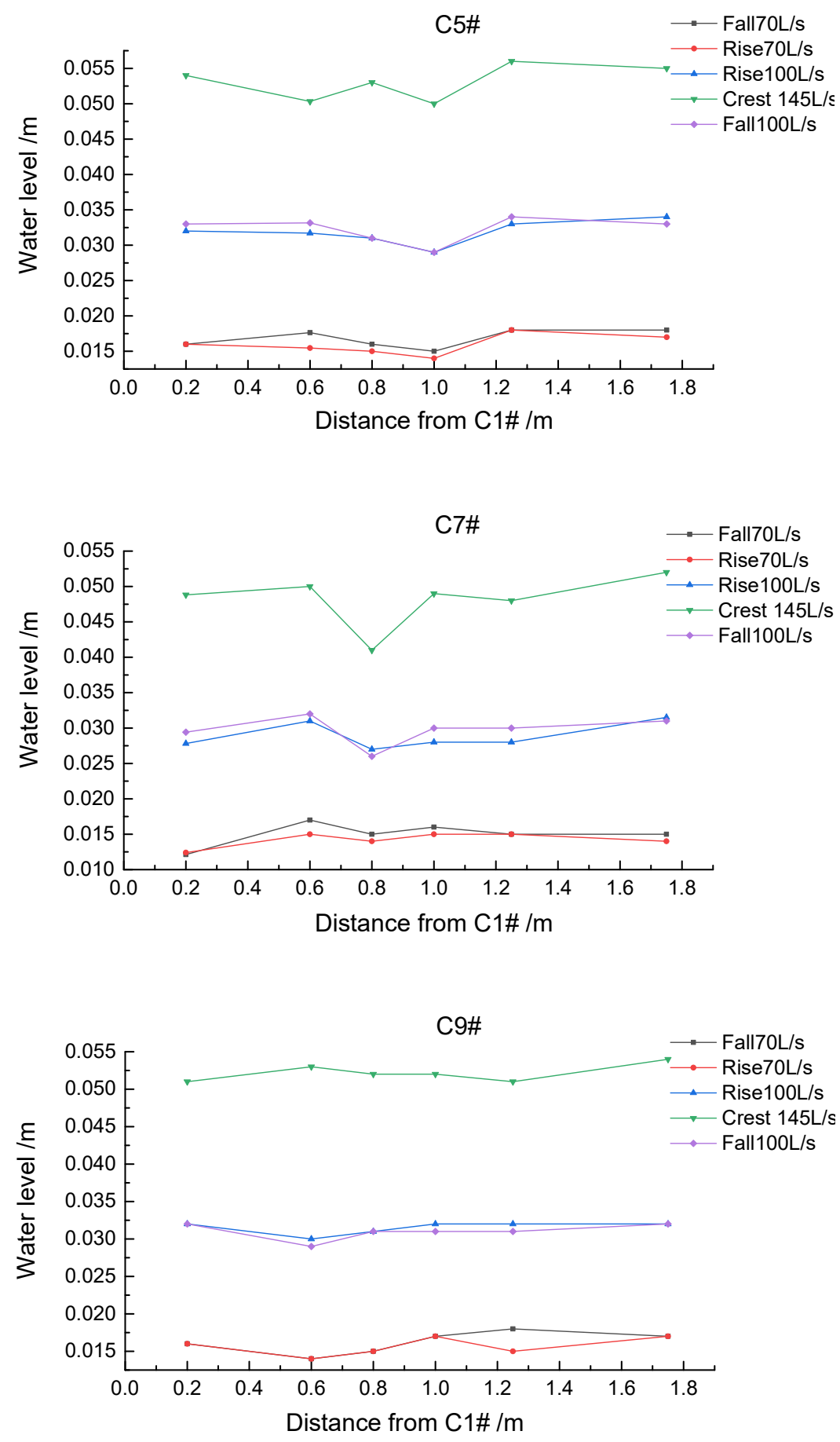


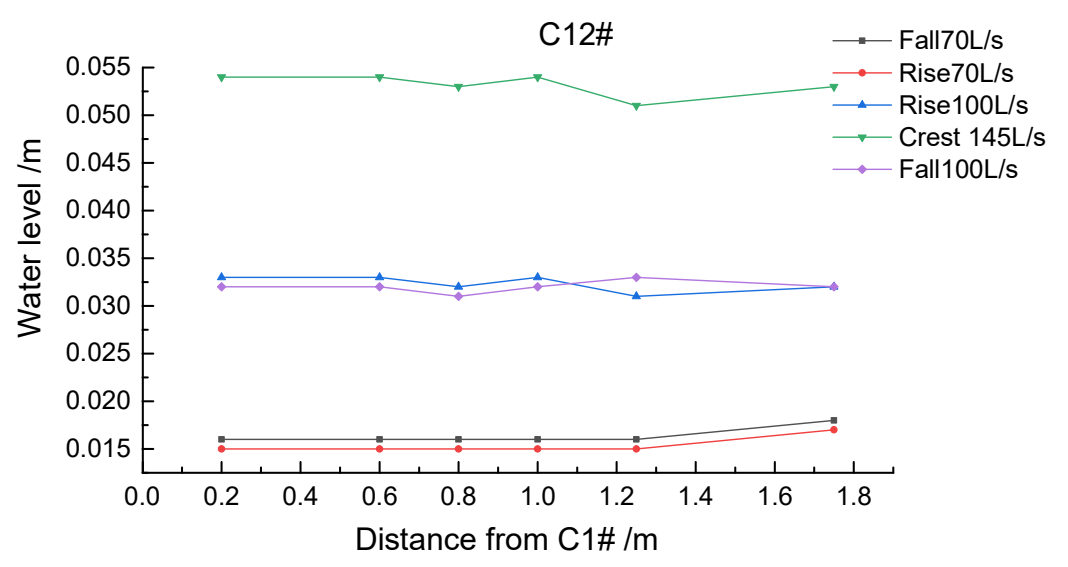

Figure 5 Transverse water surface line changes at different flow rates in case M8

Compared with the water surface line of $100 \mathrm{~L}$ rising water and 100L falling water, the variation of the water level is basically the same, that is, the maximum slope of the water surface line is basically the same, and the overall shape of the water surface line is basically the same. Similarly, the water level of each section rises by $70 \mathrm{~L} / \mathrm{s}$ and falls by $70 \mathrm{~L} / \mathrm{s}$, the water surface line also conforms to this rule, indicating that the ups and downs of the flood period have little effect on the water surface line, and the effect of the rope sleeve is not obvious, which is consistent with the longitudinal water surface line. Comparing the left and right banks of each section separately, it is found that the left bank water level is slightly higher than the right bank, that is, the water level of the beach where the beach is located is higher than the right bank. For the sections of $\mathrm{C} 1 \#$, C5\#, and C7\#, the beach body hinders the water flow. There is obvious drowning at the beachhead. The beach is located on the left bank, so that most of the water flows from the deep trough on the right bank. That is, the flow velocity on the left bank near the beachhead is smaller than that on the right bank, and the water level is slightly higher. For C9\# and C12\#, because the beach tail bend section and the left bank downstream of the beach body are in the backwater zone, the water level is slightly higher than the right bank.

The C5\# and C7\# section water surface lines have a sudden change from $0.5 \mathrm{~m}$ to $1.0 \mathrm{~m}$ from the left bank. This is due to the increase of water in the beachhead (near C1\#) and the bank where the beach is located. The water is process in the $\mathrm{C} 5 \#$ and $\mathrm{C} 7 \#$ sections. The position from $0.5 \mathrm{~m}$ to $1.0 \mathrm{~m}$ from the left bank is the curved section and steep section of the beach. Because terrain changes drastically, the curved section of the beach picks up the water flow to the right bank, which causes lateral water falling at this position. There is no sudden change in the cross-surface water line of C1\#, C9\# and C12\# sections, which is relatively flat. In particular, the C12\# section is basically a straight line, which reflects to some extent that the flow state of these sections is not changed much.

\subsection{Average flow rate distribution}

The effect of the beach on the flow velocity of the water flowing through it is very obvious. In this paper, we will analyze the influence of the shape of the shoal body and the flow rate on the average flow velocity of the water flow from the distribution of the average velocity of the longitudinal and transverse sections and the 
distribution of the average flow velocity in the survey area. The analysis of the average flow velocity of the characteristic section is mainly carried out from two aspects: the change of the flow velocity along the cross-section direction and the distribution of the flow velocity on different sections.

\subsubsection{Longitudinal section velocity distribution}

The profile of the longitudinal velocity distribution analysis is consistent with the analysis of the longitudinal section and the longitudinal waterline.The flow rate change diagram of each measuring point on the three characteristic longitudinal sections at five flow rates under case M8 is shown in Figure 6. Similarly, the influence of flow rate on the distribution law of flow velocity is mainly reflected in the numerical value, and the distribution law has no obvious change.
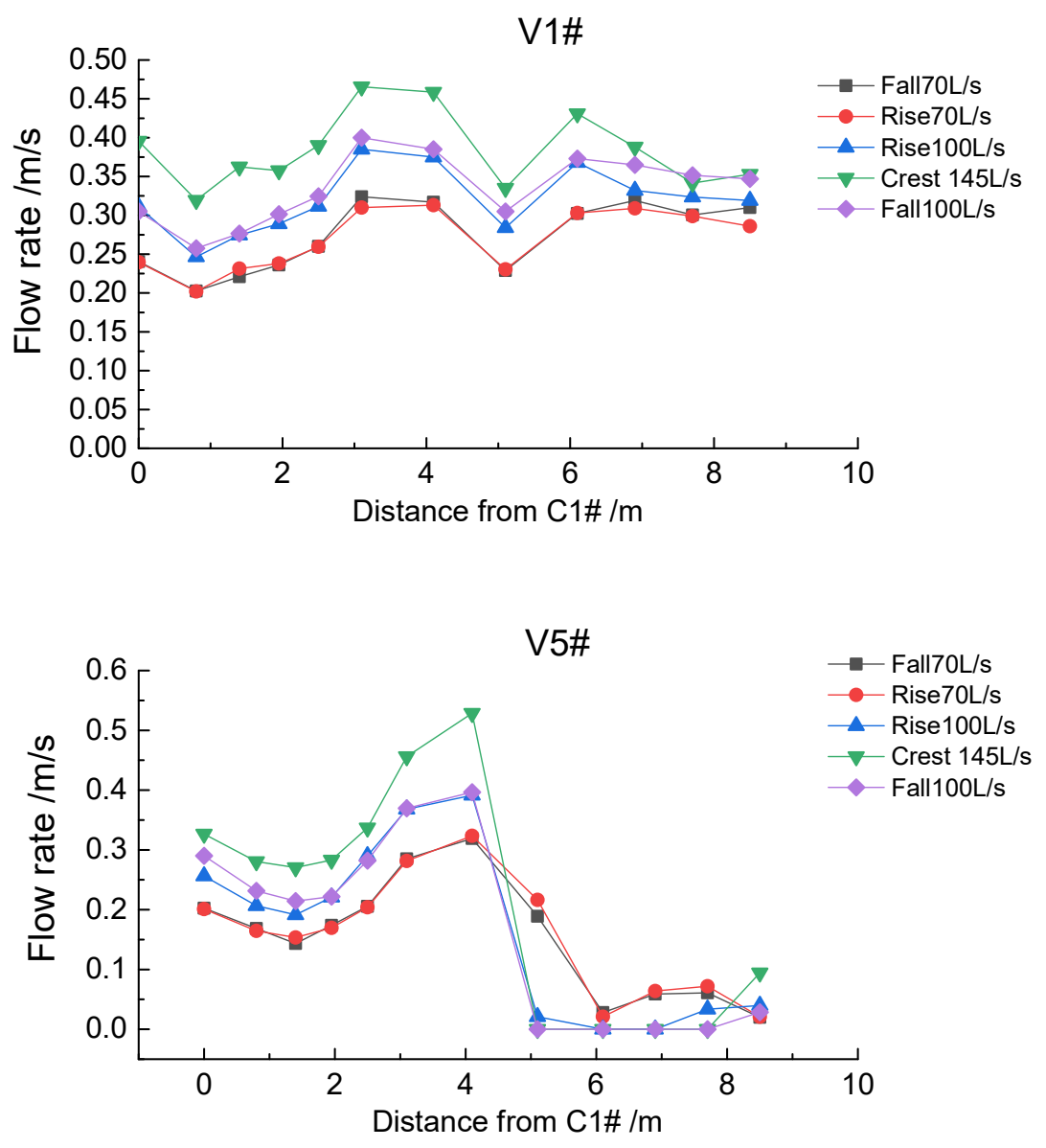


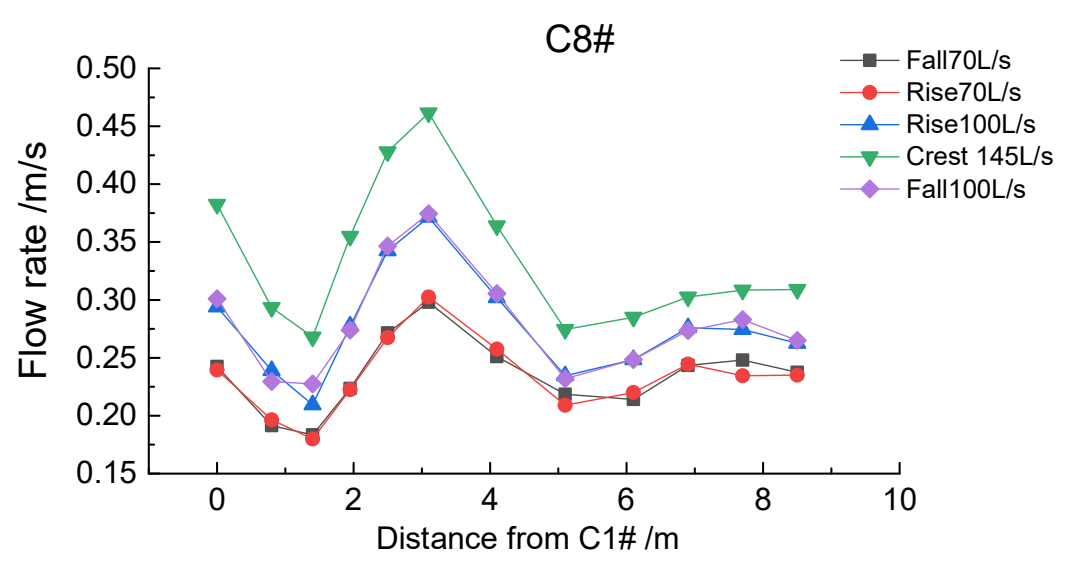

Figure 6 Flow velocity of longitudinal section of different flow in case M8

The influence of the beach body on the longitudinal flow velocity is still obvious. The performance is as follows: for the V1\# section, the flow velocity in the upstream watershed of the beach is small, and the flow velocity from the upstream to the downstream gradually increases, flowing through the beach top (around $\mathrm{C} 1 \# 4 \mathrm{~m}$ ) where the flow rate reaches the maximum value, it flows through the beach body into the backwater area of the beach. The flow velocity decreases rapidly and even decreases. For the V5\# section, the upstream of the beach body is also affected by the raise water. The flow rate is small and gradually increases along the process, but The section changes sharply through the terrain of the curved section of the shoal, and the bend flow picks up the position where the flow velocity of the section is most upstream (about C1\#3m), and then the flow velocity decreases, and the flow flows to the mainstream of the beach from the right bank to the left bank. Diffusion, the flow rate is gradually stabilized; for the V8\# section, the flow velocity in the upstream and beachhead positions of the beach is gradually increasing, but since the water flow in the section is simultaneously affected by the narrowing and jumping action of the beach, the maximum flow velocity appears at a distance of $\mathrm{C} 1 \# 3 \mathrm{~m} \sim 4 \mathrm{~m}$, the area with a large flow rate is significantly larger than $\mathrm{C} 5 \#$ and $\mathrm{C} 1 \#$.

It can be seen from the longitudinal flow velocity distribution that the upstream water flow rate of the beach body gradually increases the flow velocity along the course, and gradually decreases after the curved section and the straight section of the beach body change greatly reach the maximum value, and the bank of the tail of the beach is the main flow velocity of the bank. Larger impacts occur in the backwater zone, which tends to accumulate sediment and cause the tail to grow.

\subsubsection{Transverse section velocity distribution}

The transverse section velocity distribution analysis selected the characteristic section and the transverse water surface line analysis consistent.Figure 7 shown the flow rate change diagrams of the five characteristic flow each points of the five characteristic transverse section under case M8. From the peak flow velocity of the section, the peak flow velocity of $\mathrm{C} 1 \#, \mathrm{C} 5 \#, \mathrm{C} 12 \#$ is the smallest, C9\# is larger, and C7\# is the largest; this is the phenomenon of upstream banked-up water of beach, downstream backwater, and straight water in the beach. Consistent. 

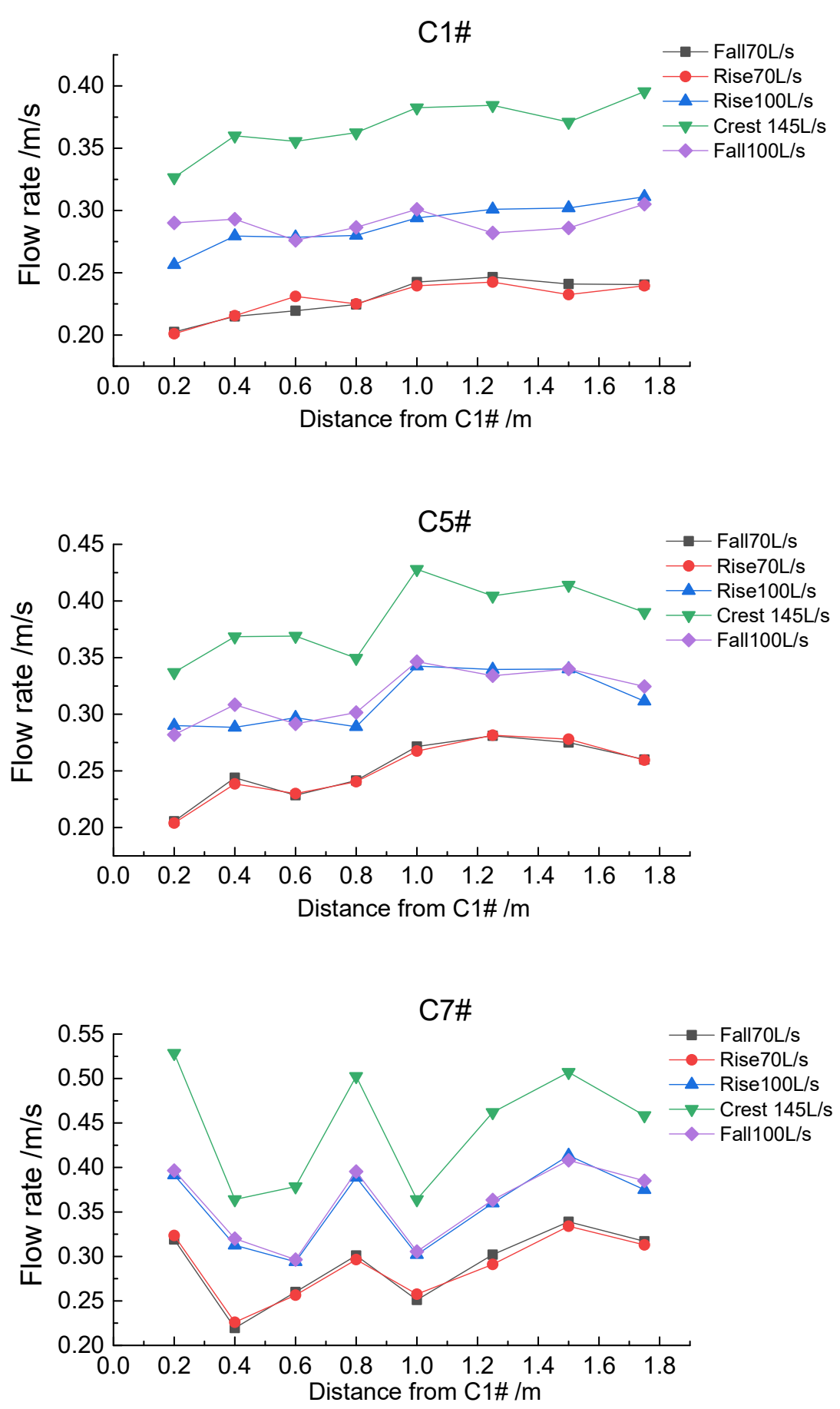

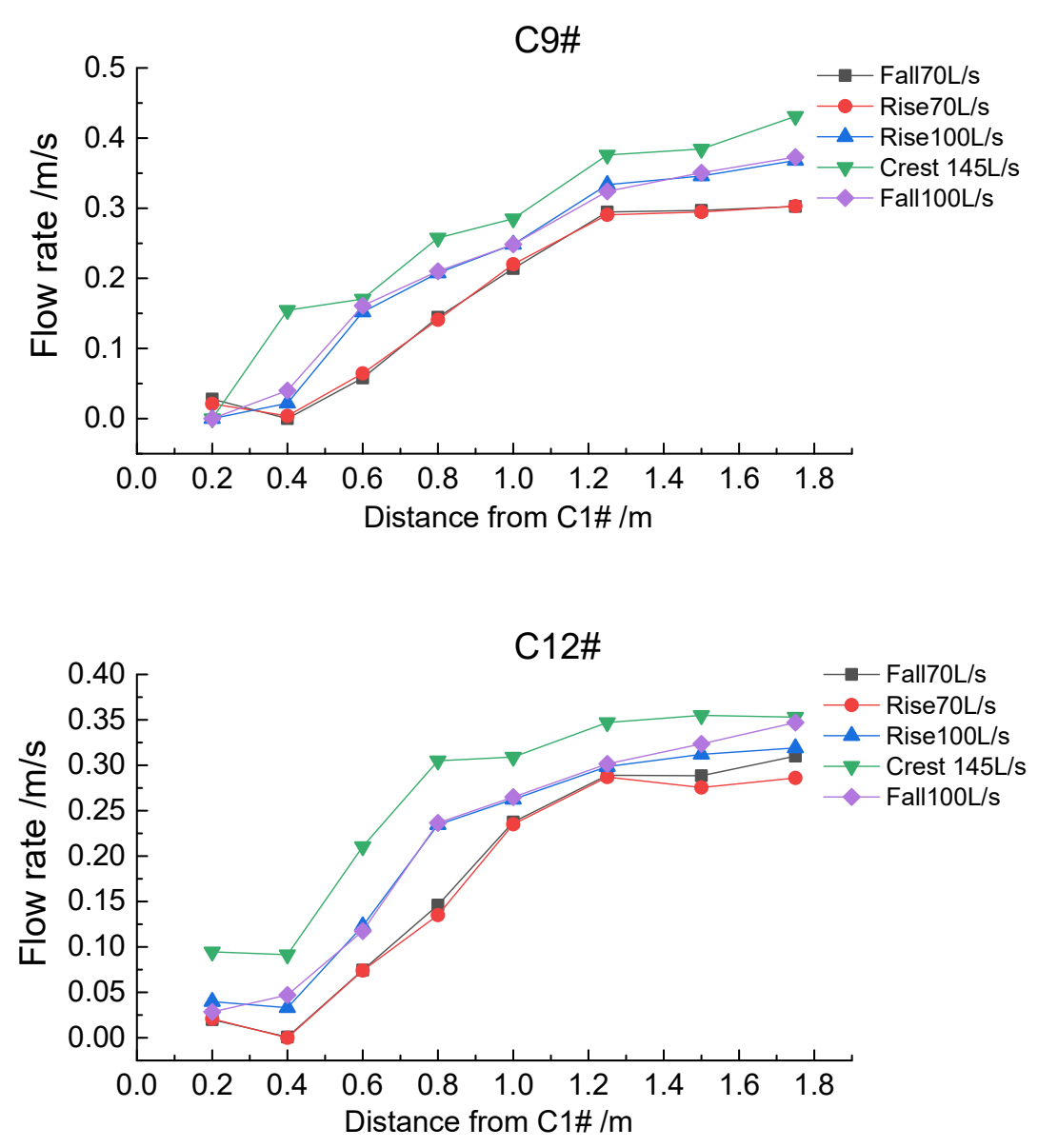

Figure 7 Flow velocity variation at different conditions of flow under M8 condition

Comparing the flow velocity distribution under the five characteristic flow rates of the same section, it can be seen that the influence of the flow rate on the flow velocity distribution of the average flow velocity in the cross section is mainly reflected in the numerical value. The larger the flow rate, the larger the flow velocity at the same position; but there is little effect on the velocity distribution law. Comparing the flow velocity distribution of the five characteristic sections of the same flow, it can be found that the flow velocity of each measuring point on the C1\# and C5\# sections is small, but only slightly increases from the left bank to the right bank, because the section is in the banked-up water, and the water flow is caused by the beach body. The effect is narrow from the left bank to the right bank, and the flow velocity on the right bank is too large; the C7\# section is located in the straight section of the beach body, the left bank passes the top of the beach, the water flow velocity is large, the right bank flows through the mainstream of the deep channel, and the flow velocity is also large; the flow velocity of each measuring point on the C9\# and C12\# section changes greatly, which is a rapid increase from the left bank to the right bank. This is because the left bank is in the backwater area of the beach, and the flow velocity in the downstream direction is very small. Some locations are even counter current, but the right bank is the mainstream, the location, the flow rate is large. 
By comparing the lateral flow velocity distribution, the beaches obviously change the distribution of the average flow velocity of the water flow in the lateral direction. The beach head and the upper part of the beach body are banked-up water, the left bank water flow is narrow to the right bank, the left bank velocity is larger than the right bank; the flat part of the middle of the beach body is the position of the beach top and the deep trough, and the left and right bank flow rates are large; the beach tail and the downstream left bank is the return water zone, the flow velocity on the left bank is small or even counter current, and the deep channel water flow begins to diverge to the left bank, and the flow velocity on the left bank is significantly smaller than that on the right bank.

\subsubsection{Distribution of flow rate throughout the whole survey area}

In order to facilitate analysis and comparison, the test can be divided into several regions according to the flow rate and the variation law. (1) Banked-up water area: The water is infiltrated into the beach head position. The water blocking effect of the beach head causes the water to be generated at the position, the flow rate is reduced, and the water flow is deflected to the deep groove position, so that the flow velocity on the left bank of the cross section is slightly smaller than the right bank; (2) In the falling water area:The falling water will occur after the flooding area, and the water will enter the position of the curved section of the beach. The flow rate changes rapidly, the water flow falls to the lowest level in the area, and the flow rate reaches the maximum. (3) The flow rate maximum zone, where the flow rate remains near the maximum value. (4) Backwater area: After the water flow reaches the lowest point, the water level gradually rises along the flow direction, and the flow velocity gradually decreases. The left bank of the area is the beach tail water return zone with the smallest flow velocity.

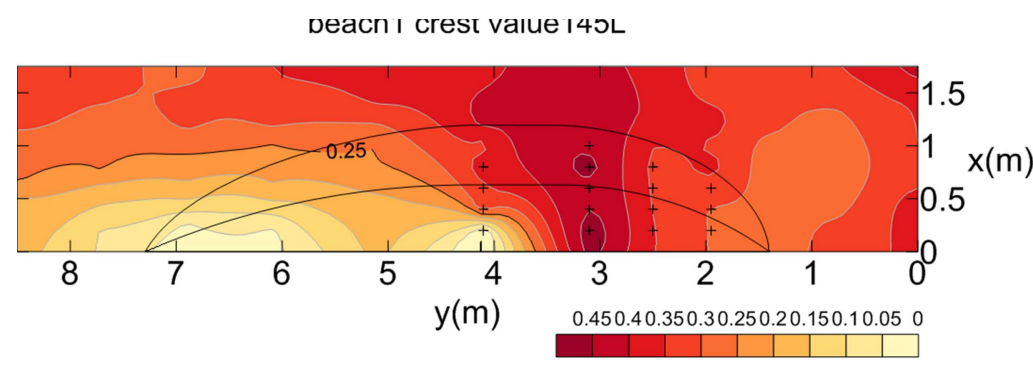

beach2 crest value145L

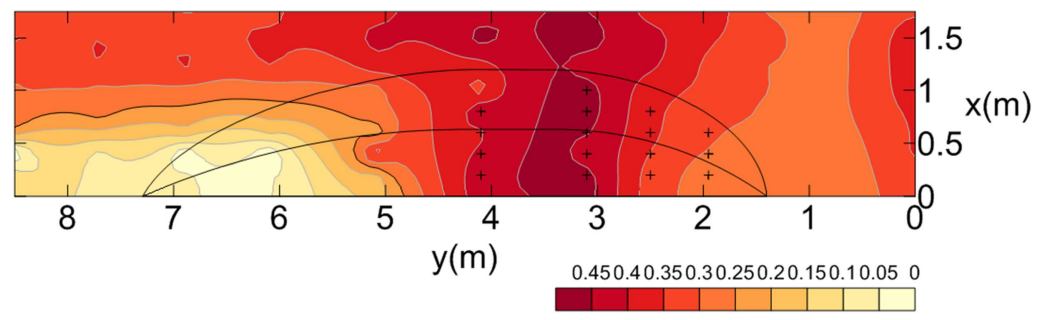

beach3 crest value145L

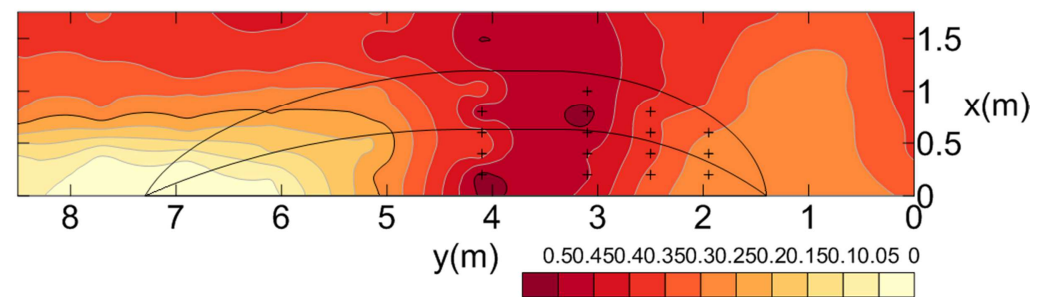


Figure 8 Velocity contour cloud map of $Q=145 \mathrm{~L} / \mathrm{s}$ (crest value) (m/s)
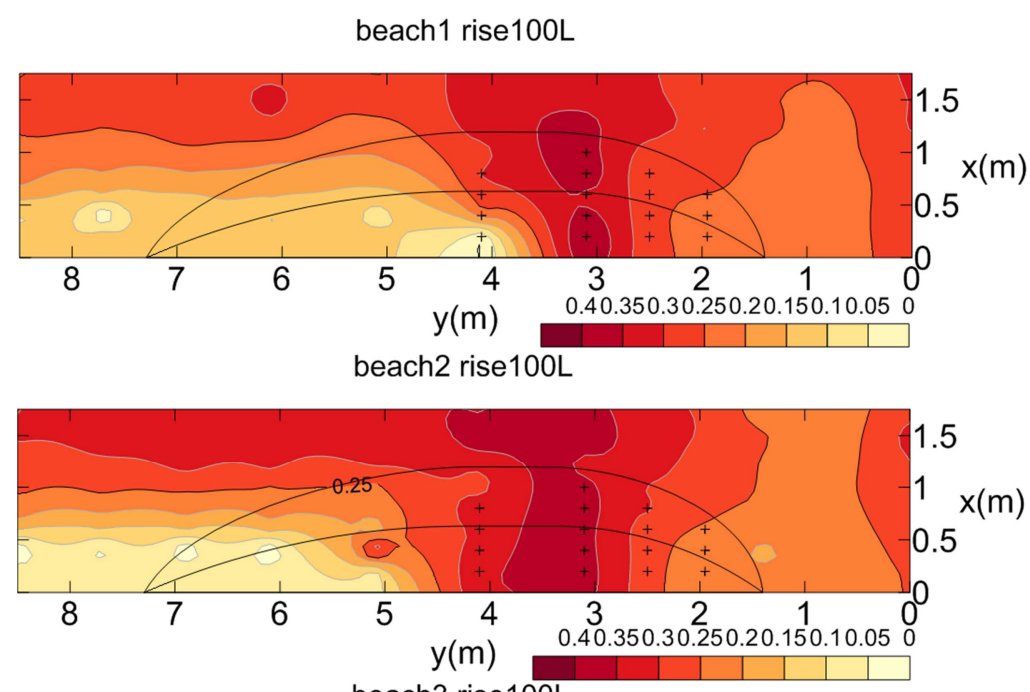

beach3 rise100L

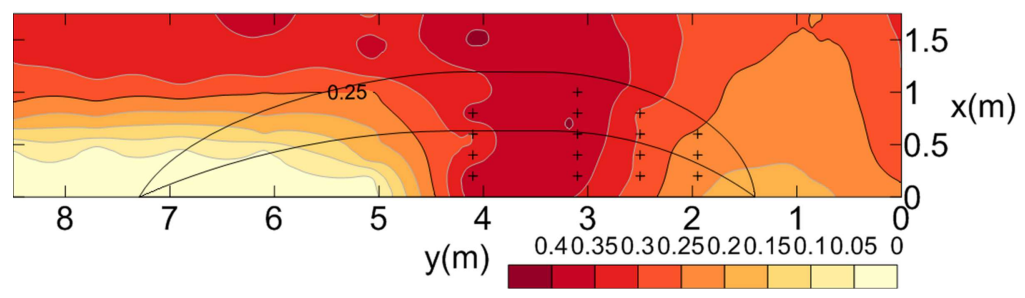

Figure 9 Velocity contour cloud map of $Q=100 \mathrm{~L} / \mathrm{s}$ when water rise $(\mathrm{m} / \mathrm{s})$ 
beah3 fall100L
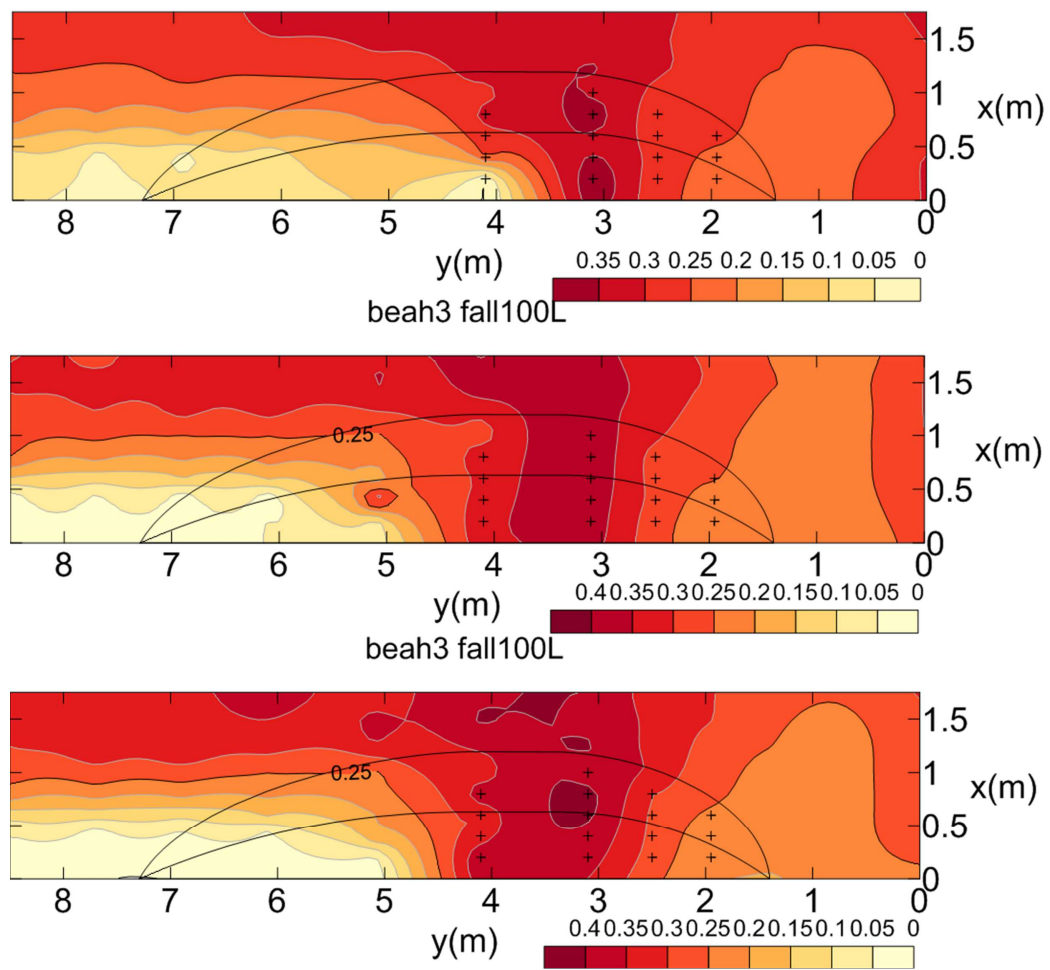

Figure 10 Velocity contour cloud map of $Q=100 \mathrm{~L} / \mathrm{s}$ when water fall (m/s)

Figure 8, Figure 9, and Figure 10 show the velocity distribution of the test area at the time corresponding to the peak flow rate of $145 \mathrm{~L} / \mathrm{s}, 100 \mathrm{~L} / \mathrm{s}$ of rising water, and $100 \mathrm{~L} / \mathrm{s}$ of falling water, respectively. The flow velocity distribution of the beaches with different steep slopes was compared in the same flow rate.

By comparison, we can find: (1) Banked-up water area. The range of the drowning area under various working conditions is basically about $y=1 \mathrm{~m}$ in the $\mathrm{Y}$-axis direction. The slope of the steep slope of the beach increases, the range of the reclamation area increases slightly, and the flow rate decreases slightly. (2) Falling water area. $y=2 \mathrm{~m} \sim 3 \mathrm{~m}$ is the area where the curved section of the beach is located. The terrain changes are complex, and the slopes in the longitudinal and transverse directions are all along the path. The contours of the flow velocity in each area of the beach are dense, and the flow velocity increases rapidly along the Y-axis. The increase is faster, and the flow rate on the left bank increases significantly faster than the right bank. (3) The maximum flow rate zone. The area of $y=3 \mathrm{~m} \sim 4 \mathrm{~m}$ is the location of the steep slope and deep trough of the shoal, and the flow velocity of each area of the shoal body is the largest. The steeper slope of the shoal body under the same flow rate, the greater the flow rate. Based on the peak flow rate of $145 \mathrm{~L} / \mathrm{s}$, the peak flow rates of the beach bodies 3,2, and 1 are respectively $v_{3 \max }>0.5 m, 0.5 m>v_{2 \max }>0.45 m, 0.5 m>v_{1 \max }>0.45 m$. Although the maximum value range of the beach body 2 and the beach body 1 is the same, the maximum value distribution area of the beach body 2 is significantly larger than the beach body 1 , and the area of the flow rate value the beach body 3 is larger than the beach body 2. In the Y-axis direction, the flow velocity values of the beaches with the flow velocity greater than $0.45 \mathrm{~m}$ are basically developed from the position of 
$y=3 m$ to the downstream, and the range gradually increases with the increase of the steep slope of the beach. (4) Backwater area. $y=6 \sim 8 \mathrm{~m}$ at the end of the beach tail, and the range of $x=0 \sim 0.5 \mathrm{~m}$ is the backwater area of the beach. There is no obvious difference between the rising and falling under the same flow rate.

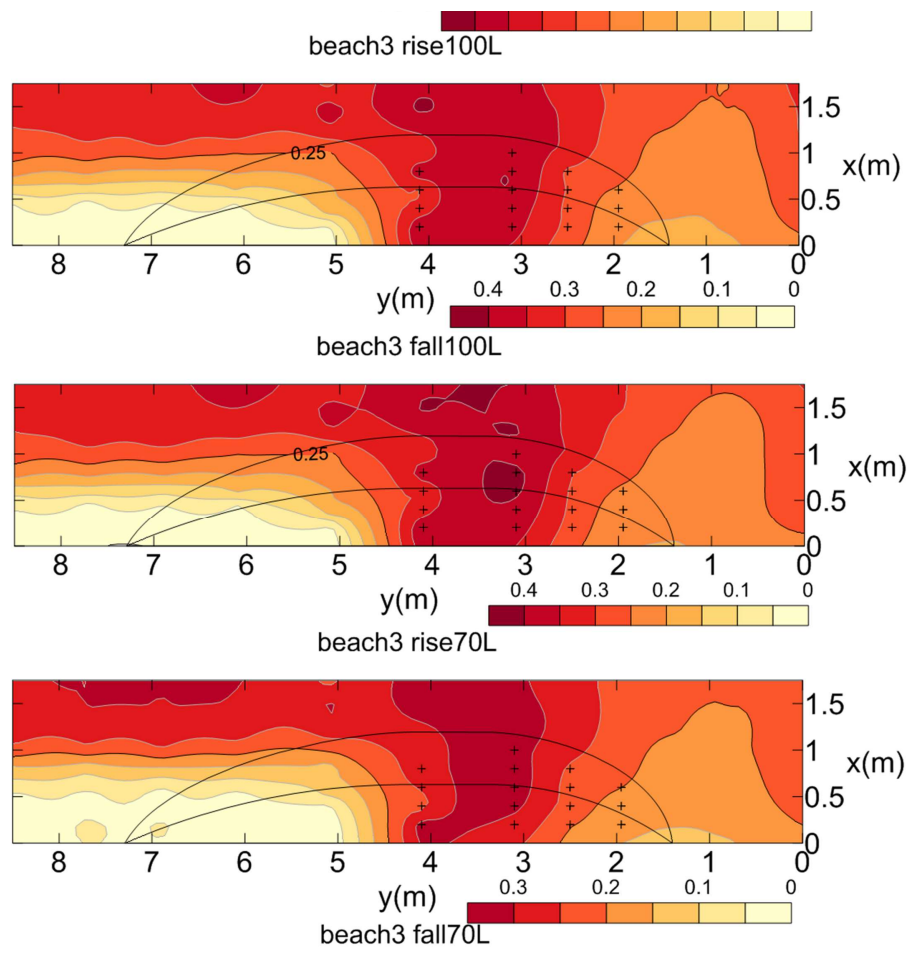

Figure 11 Contour map of beach body 3 flow process 2 different flow rates $(\mathrm{m} / \mathrm{s})$

Figure 11 shows the flow velocity distribution of the beach body 3 under five characteristic flows in the flow process 2 . It can be seen from the figure that the flow velocity distribution in the test area under each flow rate is basically the same, the flow velocity in the steep slope and deep trough area of the beach trough is the largest, the flow velocity in the beach head rake water area is small, and the flow velocity in the backwater area of the beach tail is the smallest. As the flow rate increases, the flow velocity in each area of the test area increases, and the range of each area remains basically the same. In addition, the flow velocity distribution of the same flow rate during the rise and fall of the flood peak is different. For example, the flow velocity distribution figure of the rising water $70 \mathrm{~L} / \mathrm{s}$ and the falling water $70 \mathrm{~L} / \mathrm{s}$ can be found that the range of the former in the same flow velocity region is larger or the flow velocity at the same position is larger, this is because the water flow during the rising period of the same flow rate of the non-constant flow is smaller than the water level during the water fall period, and the corresponding flow rate value is large. When the water is dropped, the upstream water is first retreated, so that the slope of the water surface is slowed down, and the corresponding flow rate value is small. 


\section{Conclusions}

Under the action of different flow rates, the trend of the longitudinal water surface along the water flow direction is basically the same; the upstream of the beach body has local water rising due to the narrow water flow of the beach body, and the water level rises; the midstream of the beach body has local water drop phenomenon, the water level decreased significantly; the water flow in the downstream of the beach body widened, the water level gradually increased and reached a stable level. For the middle and lower reaches of the Yangtze River, the water surface of the river is wide, and the single-width flow changes slowly with time, so that the water level in the corresponding position of the same flow rate is basically the same during the flood rise and full period, that is, the rope sleeve phenomenon is not significant.

It can be seen from the distribution curve of the water surface line that the influence of the flow rate on the longitudinal water surface line is mainly reflected in the maximum slope of the water surface line. The larger the flow rate, the larger the maximum slope of the water surface line, that is, the water level changes rapidly along the path. There is little influence on the trend of the water surface line, that is, the local variation of the water level is not obvious. The influence of the topography of the sink on the longitudinal water surface is mainly reflected in the trend of the water surface line. The greater the topographical change (such as the steep slope and the obvious convexity), the more severe the local variation of the water surface line.

The beaches with different steep slopes have no obvious influence on the distribution of flow velocity in the vicinity, and have a great influence on the flow velocity distribution range. The steeper the gradient of the steep slope of the beach, the wider the distribution of the maximum velocity range. The distribution of the flow velocity in the survey area can be divided into several areas according to the flow rate. The steep slope and deep trough position of the trough are the maximum flow rate. The maximum flow rate is mainly concentrated at the junction of the curved section of the beach and the straight line. Here, the water flow energy large and varied, the maintenance of the beach should be strengthened here. The flow rate decreases symmetrically along the upstream and downstream of the maximum area; the beach head water level is the median flow rate; the backwater area of the beach is the minimum flow rate area. The steeper slope of the beach-shoal boundary is the more obvious, the more obvious the effect of rising water, the more obvious the falling of water after the corresponding drowning, and the greater the turbulence intensity of the surrounding water.

Author Contributions: conceptualization,Pingyi Wang ; methodology, Pingyi Wang; resources, Pingyi Wang; data curation, Genting Guo ; writing-original draft preparation, Ye Tian; writing-review and editing,Ye Tian; funding acquisition, Meili Wang.

Acknowledgement: This work was supported by the National Inland Waterway Regulation Engineering Technology Research Center,Chongqing Jiaotong university.

Funding: Project supported by National key R \& D projects of China (Grant No. 2016YFC0402106), Chongqing basic research and frontier exploration project (Grant No. cstc2017jcyjBX0070), Chongqing "pioneer plan" innovation project (Grant No. cx2018117). 


\section{References}

1. Pingyi Wang,ZHANG Xiufang,WANG Weifeng. 2013. “Effects of the Central Bar Protection with Tetrahedron-like Penetrating Frames"[C]. Hydraulic Engineerin,2013:389-393.

2. Fazeleh Kabiri,Hossein Afzalimehr,Jueyi Sui. 2017. "Flow structure over a wavy bed with vegetation cover[J]. International Journal of Sediment Research".32(02):186-194.

3. HUA Zu-lin.2009. "Experiments do three-dimensional flow structure in braided rivers" [J]. Journal of Hydrodynamics. 21(02):228-237.

4. Ayse Yuksel Ozan. 2018. “Flow structure at the downstream of a one-line riparian emergent tree along the floodplain edge in a compound open-channel flow" [J]. Journal of Hydrodynamics.30(03):470-480.

5. ZHANG Xiufang,Pingyi Wang,YANG Chengyu. 2013. “Experimental Study on Flow Turbulence Distribution around a Spur Dike with Different Structure"[C]. Hydraulic Engineering. 2013:772-775.(in Chinese)

6. Pingyi Wang, Yang Chengyu, Yu Tao, Han Linfeng. 2016. “Study on the Stability of Channel Regulation Buildings in the Middle Yangtze River"[M]. Beijing: Science Press. 2016:1-19.(in Chinese)

7. Han Linfeng, Pingyi Wang and Su Wei. 2017. “Quantitative method and regulating effect evaluation of washout for X-shaped beach protection flexible mattress [J].Engineering Journal of Wuhan University". 2017,50(04): 487-493+499(in Chinese).

8. Liu Qianying, Pingyi Wang, Yu Tao, Liu Huaihan, Fu Zhongmin. 2009 “Study on beach protection with triangular taper penetrating frame groups" [J]. Port \& Waterway Engineering. 2009 (12): 44-48(in Chinese).

9. Liu Xiaofei, Wang Pingyi , Yang Chengyu. 2011. "Simulation technique about X-type flexible mattress[J]. Port \& Waterway Engineering". 2011 (02): 102-107(in Chinese).

10. Han Linfeng, Pingyi Wang, Liu Huaihan, Yu Tao. 2016. "Study on the stability of soft raft for Jingjiang reach under new water and sand conditions" [J]. China Water Transportation(Science \& Technology for Waterway), 2016 (01): 63-68.(in Chinese)

11. Liu Xiaofei,Pingyi Wang, Liu Huaihan, Fu Zhongmin. 2007. "Study on the trend of a typically branching and meandering channel type of middle Yangtze River" [A]. Shanghai Journal of Hydrodynamics Research and Progress, 20th National Symposium on Hydrodynamics [C]. Journal of Hydrodynamics, 2007:7(in Chinese). 